DISCUSSION

\title{
Contrary-to-Duty Scenarios, Deontic Dilemmas, and Transmission Principles*
}

\author{
Benjamin Kiesewetter
}

Actualists hold that contrary-to-duty scenarios give rise to deontic dilemmas and provide counterexamples to the transmission principle, according to which we ought to take the necessary means to actions we ought to perform. In an earlier article, I have argued, contrary to actualism, that the notion of 'ought' that figures in conclusions of practical deliberation does not allow for deontic dilemmas and validates the transmission principle. Here I defend these claims, together with my possibilist account of contrary-to-duty scenarios, against Stephen White's recent criticism.

Suppose that you ought to see your doctor and a necessary means to doing this is to take a day off work. A natural conclusion to draw is that you ought to take a day off work. This, at any rate, follows from an intuitive principle that plays an important role in a number of philosophical theories and arguments:

The transmission principle: If A ought to $\phi$, and $\psi$-ing is a necessary means for A to $\phi$, then A ought to $\psi{ }^{1}$

* Thanks to John Broome, Philip Fox, Jan Gertken, Douglas Portmore, Stephen White, the participants of Thomas Schmidt's ethics colloquium, and the Editor of Ethics, Henry S. Richardson, along with an anonymous associate editor of Ethics, for very helpful comments on an earlier draft. Work on this article has been supported by the Deutsche Forschungsgemeinschaft (DFG Project "Principles of the Deliberative Ought").

1. For references and examples of such theories, see Benjamin Kiesewetter, "Instrumental Normativity: In Defense of the Transmission Principle," Ethics 125 (2015): 92146,922 .

Ethics 129 (October 2018): 98-115

(C) 2018 by The University of Chicago. All rights reserved. 0014-1704/2018/12901-0005\$10.00 
But now suppose that if you were to take a day off work, you would not actually go to the doctor. Even though you could go to the doctor, you would in fact stay home, feel anxious, and get no work done. You might now side with John Broome, who offers the above example, and others who present similar such "contrary-to-duty scenarios," as I shall call them, in thinking that it is no longer plausible to assume that you ought to take the necessary means. ${ }^{2}$ What is the point of taking a day off if you would not in fact use it for going to the doctor (or for doing anything else you have reason to do)? Indeed, upon closer consideration you might even think that you ought to not take a day off in your circumstances. For given that you will not actually see your doctor, not taking a day off is better for you than taking a day off.

However, if you deny that you ought to take the day off in this scenario, then you are thereby committed to rejecting the transmission principle. And if you maintain that you ought to not take a day off, then you are thereby committed to rejecting another principle that seems rather plausible:

Joint satisfiability: If A ought to $\phi$ and A ought to $\psi$, then A can [ $\phi$ and $\psi]$.

This is because if taking a day off is a necessary means to seeing your doctor, then you cannot both see your doctor and not take a day off. In sum, it looks like contrary-to-duty scenarios support judgments that are inconsistent with intuitive principles like the transmission principle and the principle of joint satisfiability.

There are two philosophical views on this matter: actualism and possibilism. Actualists hold that what we ought to do can depend on what we actually do, will do, or are likely to do. Possibilists, in contrast, maintain that what we ought to do depends only on what we can do, will be able to

2. See John Broome, Rationality through Reasoning (Chichester: Wiley-Blackwell, 2013), 126. By a "contrary-to-duty scenario," I mean to refer to a scenario in which an agent is failing, or will fail, to do what she ought to do. Even though strictly speaking not all 'oughts' amount to duties or obligations, I shall allow myself in this article to use the terms 'obligation' and 'duty' to refer to 'oughts' for the sake of convenience. The term 'contrary-to-duty scenario' draws on Roderick Chisholm, "Contrary-to-Duty Imperatives and Deontic Logic," Analysis 24 (1963): 33-36, who proposes a number of such cases himself. The most widely discussed contrary-to-duty scenario is presumably the example of Professor Procrastinate offered by Frank Jackson and Robert Pargetter, "Oughts, Options, and Actualism," Philosophical Review 95 (1986): 233-55, 235, which is in turn inspired by Holly Goldman, "Doing the Best One Can," in Values and Morals, ed. Alvin I. Goldman and Jaegwon Kim (Dordrecht: Reidel, 1978), 185-214, 185-86. Some philosophers worry that the assumption that you ought to do something and that it is already true that you will not do so are in conflict (for a brief discussion, see Kiesewetter, "Instrumental Normativity," 928). If you share this worry, then please feel free to substitute, throughout this article, the assumption that you are likely or unlikely to do something for the assumption that you will or will not do it. 
do, or are likely to be able to do. ${ }^{3}$ If possibilism is true, then whether you will actually go to the doctor is irrelevant for the question of whether you ought to take a day off-all that matters is whether you can go. Possibilists thus maintain that you ought to take the day off even if you will not actually go to the doctor, thereby preserving the transmission principle and the principle of joint satisfiability. By contrast, actualists maintain that whether you ought to take a day off work or not depends on what you would actually do if you took a day off. Since you would not actually see your doctor, actualists believe that you should not take a day off. At the same time, however, actualists don't want to go so far as to claim that the fact that you will not see your doctor provides a justification for not seeing your doctor itself-surely, mere reluctance to perform an action is not sufficient to escape an obligation to perform that action. ${ }^{4}$ And so actualists hold on to the assumption that you ought to see your doctor while also claiming that you ought to not take a day off; they take contrary-toduty scenarios to constitute deontic dilemmas. ${ }^{5}$

My aim in this article is to support the possibilist verdict on this matter. I will do so by clarifying an argument for joint satisfiability and an argument for the transmission principle that I have submitted in an earlier article, and I will defend these arguments, together with my proposed possibilist treatment of contrary-to-duty scenarios, against Stephen White's recent criticism. ${ }^{6}$ At the core of these arguments is a concern with practi-

3. This is a broader conception of the actualism/possibilism distinction than the one I used in Kiesewetter, "Instrumental Normativity," 926, which I adopted from Jackson and Pargetter, "Oughts, Options, and Actualism," and which presupposes a consequentialist framework. Actualist accounts include Holly Goldman, "Dated Rightness and Moral Imperfection," Philosophical Review 85 (1976): 449-87; and Jackson and Pargetter, "Oughts, Options, and Actualism." Possibilism is defended, among others, in Goldman, "Doing the Best One Can"; and Michael Zimmerman, The Concept of Moral Obligation (Cambridge: Cambridge University Press, 1996), chap. 6.

4. Goldman ("Dated Rightness and Moral Imperfection") is a notable exception of an actualist who does go this far (and thus of a form of actualism that is compatible with the transmission and joint satisfiability principles). However, this implication of her view has led Goldman to ultimately reject actualism in favor of a form of possibilism; see Goldman, "Doing the Best One Can," 198-200.

5. By a "deontic dilemma," I am referring to a situation in which an agent is subject to obligations that are not jointly satisfiable. Not all deontic dilemmas of this sort are tragic in the sense that they imply that agents are guilty of wrongdoing no matter what they do. As Jackson and Pargetter, "Oughts, Options, and Actualism," 242-44, emphasize, actualists are not committed to the existence of such tragic dilemmas. Even though actualists say that you ought to see your doctor and that you ought to not take a day off, they also say that you can [take a day off and see your doctor]. If you do this, it will no longer be true that you ought to not take a day off, and you will not have violated an obligation. Thus, while actualists take contrary-to-duty scenarios to constitute deontic dilemmas, they do not take them to constitute tragic dilemmas.

6. See Kiesewetter, "Instrumental Normativity"; and Stephen White, "Transmission Failures,” Ethics 127 (2017): 719-32. 
cal reasoning. In my view, a notion of 'ought' that allows for deontic dilemmas is unsuitable for deliberation about what to do; it cannot be the concept of 'ought' that we use in conclusions of practical deliberation. And if contrary-to-duty scenarios do not provide counterexamples to the claim that joint satisfiability is valid for the deliberative notion of 'ought', they also do not seem to provide counterexamples to the claim that the transmission principle is valid for the deliberative notion of 'ought'. As far as the deliberative 'ought' is concerned, we need an account of contrary-toduty scenarios that is compatible with both of these principles.

Following the order of White's discussion, I will begin by presenting my possibilist account of contrary-to-duty scenarios and argue that White's critique of this account is mistaken (Sec. I). Subsequently, I will clarify my central argument for joint satisfiability and defend it against White's objections (Sec. II). Finally, I will turn to my positive argument for the transmission principle, according to which this principle is entailed by the best explanation of joint satisfiability. While I agree with White that my original argument can reasonably be questioned, I here present a modified version that avoids this complaint (Sec. III).

\section{A POSSIBILIST ACCOUNT OF CONTRARY-TO-DUTY SCENARIOS}

A contrary-to-duty scenario, in the sense relevant for our discussion, is a case that satisfies four conditions, here exemplified by Broome's example:

(i) You ought to see your doctor.

(ii) Taking a day off is a necessary means for you to see your doctor.

(iii) If you won't see your doctor, then taking a day off will make things worse.

(iv) You won't see your doctor.

Actualists claim that because of (iii), we should accept the following conditional obligation with narrow scope: ${ }^{7}$

(N) If you won't see your doctor, then you ought to not take a day off.

7. Actualism, as I have defined it above, does not entail that $(\mathrm{N})$ holds true in all instances of (i)-(iv). Nonteleological actualists, who think that we are sometimes permitted or obliged to make things worse, will reject this claim. For example, they might claim that if you have promised to take a day off, (N) might be false even if (i)-(iv) are true. But the relevant examples under discussion abstract from potential nonteleological reasons of this sort, and so actualists will, insofar as they accept teleological reasons, in fact accept (N). 
Such conditional obligations are detachable by modus ponens, that is, we can derive the following conclusion:

(C) You ought to not take a day off (from (iv) and (N)).

However, since (i) says that you ought to see your doctor and (ii) entails that you cannot [see your doctor and not take a day off], (C) violates joint satisfiability.

In my article "Instrumental Normativity," I argued that we can reject the actualist treatment of contrary-to-duty scenarios and still make sense of an important pretheoretical intuition that we have about such cases, namely, that you get something right when refraining from taking a day off in circumstances (i)-(iv). How can this be if the transmission principle entails that you ought to take a day off in such circumstances? Well, because refraining from taking a day off might be a way of complying with a wide-scope obligation along the following lines:

(W) You ought to make sure that [if you won't see your doctor, then you don't take a day off].

Just like (N), (W) explains why refraining from taking a day off amounts to complying with an obligation. In contrast to $(\mathrm{N})$, however, $(\mathrm{W})$ does not entail that you ought to refrain from taking a day off. And so (W) can capture the pretheoretical intuition that you get something right when you don't take a day off in a way that is compatible with both joint satisfiability and the transmission principle.

Against this proposal, White argues that it cannot accommodate the normative relevance of the fact that taking a day off will make things worse:

The problem is that $(\mathrm{W})$ seems to follow directly from the fact that you ought to see your doctor. If you ought to see your doctor, then you ought to make it true that, if you will not see your doctor, you do not take the day off, precisely by making the antecedent of that conditional false. But if that's right, then it's just irrelevant to the truth of $(\mathrm{W})$ that it would be bad (pointless, anxiety-producing, etc.) if you were to take the day off without going to the doctor. . . . Even if $(\mathrm{W})$ is true, it does not, therefore, seem to account adequately for the intuition that the benefits of going to work versus just sitting at home are in some way normatively significant. ${ }^{8}$

In a nutshell, White's objection to my treatment of contrary-to-duty scenarios is that $(\mathrm{W})$ cannot account for the normative relevance of (iii),

8. White, "Transmission Failures," 724. 
since (W) follows from (i) alone and holds independently of whether (iii) is true. ${ }^{9}$ While actualists can say that (iii) is normatively relevantas they maintain that $(\mathrm{N})$ holds because of (iii) - White thinks that possibilists cannot say the same about $(\mathrm{W})$.

But why does White believe that (W) follows from (i) alone? His claim seems to rest on two assumptions. The first assumption is that your going to the doctor implies that you make sure that [if you won't go to the doctor, then you don't take a day off]. This follows from what we might call the deflationary understanding of the 'making sure' locution, according to which if your $\phi$-ing logically implies a proposition $p$, then your $\phi$ ing also implies that you make sure that $p$. Since your seeing your doctor logically implies that [if you won't see your doctor, then you don't take a day off], it follows that your seeing your doctor also implies that you make sure that [if you won't see your doctor, then you don't take a day off].

The second assumption, which is common in Standard Deontic Logic, is that obligations are closed under logical implication:

Closure: If A ought to $\phi$, and $\phi$-ing implies $\psi$-ing, then A ought to $\psi$.

Since on the first assumption your seeing the doctor implies your making sure that [if you won't see your doctor, then you don't take a day off], the closure principle validates the inference from (i) to (W).

However, the fact that White's reasoning rests on these assumptions reveals a number of problems with his objection. The first thing to note here is that closure is independently very controversial and cannot be taken for granted without further argument. The closure principle is subject to Ross's paradox, as it licenses the counterintuitive inference from 'you ought to send the letter' to 'you ought to send the letter or burn it', which many philosophers regard as invalid..$^{10}$ Possibilists are free to reject it on these grounds, thereby rebutting White's objection.

The second point to note is that the closure principle is incompatible with the actualist treatment of contrary-to-duty scenarios, which means that White cannot consistently appeal to it. To see this, add to our scenario

9. It is worth noting that this is exactly Chisholm's argument to the effect that within the standard systems of deontic logic, contrary-to-duty imperatives cannot be represented by a wide-scope propositional operator that ranges over a conditional. See Chisholm, "Contraryto-Duty Imperatives," 34. See also Jackson and Pargetter, "Oughts, Options, and Actualism," 239.

10. See, e.g., Sven Danielsson, "Taking Ross's Paradox Seriously: A Note on the Original Problems of Deontic Logic," Theoria 71 (2005): 20-28; and John Broome, "Requirements," in Hommage à Wlodek. Philosophical Papers Dedicated to Wlodek Rabinowicz, ed. Toni Rønnow-Rasmussen et al. (Department of Philosophy, Lund University, 2007), 1-41, 19 22, http:/ /www.fil.lu.se/hommageawlodek/. For the original paradox, see Alfred Ross, "Imperatives and Logic," Theoria 7 (1941): 53-71. 
the assumption that you ought to [take a day off and see your doctor]. The actualist will still maintain that given what would actually happen if you took a day off, you ought to not take a day off. This means that, besides the transmission and joint satisfiability principles, actualists also have to reject the following:

Distribution: If A ought to [ $\phi$ and $\psi]$, then A ought to $\phi$ and A ought to $\psi .^{11}$

However, as $\phi$-ing and $\psi$-ing are each implied by [ $\phi$-ing and $\psi$-ing], distribution follows from closure. Appealing to closure in rejecting my treatment of contrary-to-duty scenarios thus renders White's position inconsistent. ${ }^{12}$

Third, it is also open for possibilists to reject the deflationary interpretation of the 'making sure' locution in (W). On an alternative understanding, seeing the doctor is not sufficient to make sure that (if you won't see the doctor, then you don't take a day off); further conditions-for example, that you take additional measures to ensure this conditional, or that you act out of a recognition of the reasons that count specifically in favor of making the conditional true (rather than in favor of making the antecedent false)—would be necessary. ${ }^{13}$ On such a substantial reading of the 'making sure' locution, (W) could not be derived from (i) even if one assumes the closure principle.

I conclude that there is no reason to suppose that my treatment of contrary-to-duty scenarios cannot accommodate the normative signif-

11. This is a well-known point; see, e.g., Jackson and Pargetter, "Oughts, Options, and Actualism," 247; and Zimmerman, Concept of Moral Obligation, 191.

12. Strictly speaking, White's claim that (i) entails (W) presupposes a principle that is logically weaker than closure, namely, disjunction introduction, i.e., $\vdash(\mathrm{O}(p) \rightarrow \mathrm{O}(p \vee q))$, which does not by itself entail distribution. It is difficult to see, however, why one would allow for disjunction introduction but not for conjunction elimination within the 'ought' operator, given that the former principle is much less intuitive than the latter. Moreover, as John Broome pointed out to me, disjunction introduction entails distribution on the assumption that 'ought' allows for the substitution for logical equivalents - an assumption that Paul McNamara calls "the most fundamental and least controversial rule of inference in deontic logic"; see Paul McNamara, "Deontic Logic," in The Stanford Encyclopedia of Philosophy, ed. Edward N. Zalta (Stanford, CA: Stanford University, 2014), 1-128, sec. 1.3, http://plato .stanford.edu/archives/spr2014/entries/logic-deontic/. By disjunction introduction, $\mathrm{O}(p \& q)$ entails $\mathrm{O}(p \& q \vee \neg q)$, which in turn entails $\mathrm{O}(p)$ by substitution of logical equivalents.

13. See Kiesewetter, "Instrumental Normativity," 937. Note that on the substantial reading of the 'making sure' locution, it no longer follows from (W) that you get something right just because you don't take a day off. I don't think that this is an objection to this way of understanding (W), however. If you don't take a day off by accident or because of laziness, then it might be more accurate to say that you're lucky rather than that you get something right. The intuition to be vindicated, I take it, is concerned with the case in which you refrain from taking a day off out of a recognition of the fact that you would otherwise make things worse. 
icance of the fact that the agent would make things worse if she took the means. Just as actualists can say that $(\mathrm{N})$ holds because of (iii), possibilists can say the same about (W). For example, possibilists might hold that since you would make things worse by taking a day off and not going to the doctor, making sure that you don't do that is part of the overall best means of avoiding a really bad outcome, and therefore something that you have good reason to do- a reason that is not defeated in the relevant examples. ${ }^{14}$

Finally, possibilists can account for the normative significance of (iii) even if they accept that (W) is trivially implied by (i). ${ }^{15}$ This is because they can plausibly claim that even if the truth of (W) does not depend on (iii), (iii) explains why in the circumstances described it is more important to satisfy (W) than to satisfy (i). If failing to see the doctor while taking the means is worse than just failing to see the doctor, then (other things being equal) the obligation to avoid the first failure is more important than the obligation to avoid the second failure. In order for (iii) to be normatively relevant, it suffices to assume that it explains this fact about the relative importance of obligations; one need not assume that it explains the existence of an obligation.

\section{THE ARGUMENT FROM IMPOSED IRRATIONALITY}

I shall next turn to my central argument for the claim that joint satisfiability is a valid principle for the 'ought' used in practical deliberation. The argument is based on the assumption that the deliberative 'ought' is the sense of 'ought' that figures in the so-called enkratic principle, according to which it is irrational to believe that one ought to do something while at the same time refraining from intending to do it. ${ }^{16}$ With respect to the notion of 'ought' that is subject to the enkratic principle, the assumption of deontic dilemmas seems to impose practical irrationality on those who believe the truth about what they can and ought to do, for if we believe these truths in a deontic dilemma, we must either fail to intend the action we believe we ought to perform or have inconsistent intentions

14. Note that this argument does not likewise deliver the conclusion that you ought to not take a day off. Not taking a day off is a sufficient means to avoiding the relevant outcome, but since it also prevents you from doing something that you ought to do, it is not plausibly part of the overall best means to doing so. Moreover, according to the possibilist, any reason for not taking a day off will be defeated by the reasons to see the doctor.

15. Thanks are due to an associate editor of Ethics for pointing this out to me.

16. See esp. Broome, Rationality through Reasoning, 22-25. The enkratic principle is plausibly subject to further conditions (for discussion, see Broome, Rationality through Reasoning, 159-72). I ignore these conditions here because they are irrelevant in the present context. 
(i.e., intentions for actions we believe are incompatible). ${ }^{17}$ This, one might think, is absurd.

The following is a way to spell out this argument in more detail than I have done before:

(1) Rational immunity: For all agents A, and all truths about what A can and ought to do, it is not the case that if A believes these truths, then, because of that, A is practically irrational (assumption).

(2) If A believes that she herself ought to $\phi$, that she herself ought to $\psi$, and that she herself cannot [ $\phi$ and $\psi]$, then, because of that, A is practically irrational (assumption).

(3) A ought to $\phi$, and A ought to $\psi$, and A cannot [ $\phi$ and $\psi]$ (assumption for reductio).

(4) It is not the case that necessarily, if A believes that she herself ought to $\phi$, and that she herself ought to $\psi$, and that she herself cannot $[\phi$ and $\psi]$, then, because of that, $\mathrm{A}$ is practically irrational (from 1 and 3).

(5) It is not the case that A ought to $\phi$, and A ought to $\psi$, and A cannot $[\phi$ and $\psi]$ (reductio of 3 , by contradiction between 2 and 4 ).

White objects that in the relevant contrary-to-duty scenarios, agents are subject to deontic dilemmas because they are practically irrational in the first place. He illustrates this point by Broome's example:

Recall that this is not a case in which you will fail to do as you should (i.e., visit your doctor) because you will be prevented from doing so. It is, rather, a case in which you cannot bring yourself to intend and act as you judge you should. You are akratic. It's as a result of this failure of practical rationality that, according to the actualist interpretation, you ought to do something incompatible with seeing the doctor - namely, go to work. Suppose, then, you believe that because you won't see your doctor (although you should) you should not take the day off. This normative belief is not the source or cause of your irrationality but a response to it. What seemed absurd was the idea

17. As I have learned in the meantime, Douglas Portmore, Commonsense Consequentialism: Wherein Morality Meets Rationality (Oxford: Oxford University Press, 2011), 181-82, presents a related argument against deontic dilemmas. One important difference between our arguments is that Portmore assumes that in the relevant contrary-to-duty scenarios, " $\mathrm{S}$ ought to intend to $\phi$ if S . . ought to $\phi "(181)$, while my argument merely assumes that it is irrational not to intend what one believes one ought to do (the enkratic principle). Actualists are likely to reject Portmore's assumption on the basis of the same considerations that motivate their other judgments in contrary-to-duty scenarios: they will say that there is no point in intending an action one will not actually perform, and so deny that one ought to intend the actions one ought to perform in contrary-to-duty scenarios. My argument does not, I think, invite a reply of this sort. 
that judging correctly what you ought to do could itself prevent you from being fully rational. But that is not what is happening in the current case. ${ }^{18}$

The first thing to note about this reply is that it is based on the assumption that the relevant counterexamples are cases of akrasia. This is surprising, as it is not an essential aspect of a contrary-to-duty scenario that the agent believes that she violates an obligation. It is also not an essential part of Broome's particular example. For suppose that you do not believe that you ought to see your doctor. In this case, the fact that you won't see your doctor does not show that you are akratic. But the actualist will still insist that, given that you would sit around in anxiety instead of going to the doctor when taking a day off, you ought not to do it. Taking a day off does not become more sensible if we assume that you do not believe that you ought to see your doctor; if anything, it becomes less sensible. More generally speaking, it seems to be an unstable position to think that the actualist verdict is correct in akratic contrary-to-duty scenarios but not in nonakratic contrary-to-duty scenarios. If that is so, then a defense of the actualist verdict should not rely on the assumption that the relevant counterexamples are cases of akrasia.

White's response might be rescued on the basis of a more general theory according to which all failures to do what one ought to do, and thus all contrary-to-duty scenarios, involve failures of rationality (though not necessarily akratic failures). This is a controversial view, but it is not without support, and in what follows I shall grant it for the sake of the argument. ${ }^{19}$

But how does this assumption undermine the argument from imposed irrationality: by calling into question rational immunity, or by suggesting that rational immunity is not in conflict with the actualist treatment of contrary-to-duty scenarios? Does White reject premise (1) or premise

18. White, "Transmission Failures," 728. I take it that White does not literally mean to say that "you cannot bring yourself to intend and act as you judge you should" (my emphasis). Otherwise, the actualist verdict that you ought to go to work would be conditional on your not being able to form the intention to see the doctor. But in this case, possibilists can plausibly argue that it is no longer the case that you ought to see your doctor, and that the verdict that you ought to go to work is not in conflict with joint satisfiability or the transmission principle. This is because if you lack the ability to intend an action, you seem to lack control over whether you perform that action, which in turn seems a plausible condition for its being the case that you ought to perform it. Moreover, White explicitly accepts this kind of response in other cases in which failure to conform to an obligation lies "outside of your control" (720 n. 2). All that White needs to assume, and should assume, is that you do not intend and act as you judge you should.

19. Broome, Rationality through Reasoning, chap. 5, explicitly denies that failures to respond correctly to reasons (and thus failures to do what one ought to do) must involve failures of rationality, while I myself am sympathetic to this view; see Benjamin Kiesewetter, The Normativity of Rationality (Oxford: Oxford University Press, 2017). 
(2) of the argument? On the first reading, White holds that we should allow for situations in which an agent's true normative beliefs force her to make a rational mistake if only these situations themselves result from a rational mistake. This does not strike me as a plausible position. Why should the fact that you've made a rational mistake be a reason to expect that believing the normative truth could commit you to making yet another rational mistake? As Broome himself argues in a related context, "we should expect rationality to require you to get out of your irrational state, not to get in deeper." ${ }^{20}$ In any case, White never asserts that rational mistakes provide an exception to rational immunity, nor does he provide reasons for thinking so, and hence I will disregard this interpretation of his objection in what follows. ${ }^{21}$

On the second reading, White does not object to rational immunity; rather, he aims to show that rational immunity is compatible with the actualist rejection of joint satisfiability, and thus denies premise (2). Accordingly, White maintains that while agents are irrational when they believe the truth about what they can and ought to do in a contrary-to-duty scenario, they are not irrational because they believe these truths-rather, they believe these truths because they are irrational in the first place. As he puts it, such beliefs are "not the source or cause of ... irrationality but a response to it." 22

The problem with this version of the objection is that the beliefs might be both a response and a source of irrationality. More precisely, they could be both a response to one rational mistake and a source of a second rational mistake. In fact, this seems to be a very accurate description of what is going on according to White's view. You start off with an obligation to $\phi$, which you are going to violate. According to White, this shows that you are failing to be rational. Due to this failure of rationality, you come to have an obligation to not take the necessary means to $\phi$-ing, and you can truly form beliefs in incompatible obligations. Although these beliefs are in one respect a response to a rational mistake (where this failure consists in violating your obligation to $\phi$ ), they are also the source of a further rational mistake, for as long as you hold these beliefs, you must either be akratic with respect to one of them or have intentions that you know to be inconsistent.

Thus, even if joint satisfiability fails only in cases of a preceding rational mistake, it does not follow that its failure is not the source of a further rational mistake. And so the assumption that contrary-to-duty scenarios involve a rational mistake does nothing to undermine premise (2) - the

20. John Broome, "Wide or Narrow Scope?," Mind 116 (2007): 359-70, 365.

21. In personal communication, White has confirmed that he did not intend to question rational immunity.

22. White, "Transmission Failures," 728. 
assumption that agents believing in conflicting obligations are practically irrational because they have the beliefs that they have.

In the context of distinguishing the two relevant rational mistakes at issue, it may be worth noting that premise (1) does not state the following:

(1)* For all agents A, and all truths about what A can and ought to do, it is not the case that necessarily, if A believes these truths, then $\mathrm{A}$ is practically irrational.

White might legitimately complain about $(1) *$ that if there are truths about what A ought to do that apply to A only because A fails to be rational, then it might well be impossible to believe these truths while being rational. He might argue that (1)* presupposes that A's obligations don't depend on whether A fails to be rational-an assumption that seems to beg the question against actualism. However, this complaint does not apply to rational immunity. It is one thing to accept that obligations can apply in virtue of a kind of rational mistake, and it is quite another thing to accept that agents can be forced into making a rational mistake by way of believing the truth about their obligations. The assumption that obligations can apply to agents in virtue of their failure to be rational thus provides no reason for rejecting rational immunity, and further reasons are not mentioned by White. The argument from imposed irrationality is not called into question by the assumption that contrary-to-duty scenarios involve rational mistakes.

\section{REASON TRANSMISSION}

My main aim in "Instrumental Normativity" was to defend the transmission principle against the actualist treatment of contrary-to-duty scenarios, but in the end I also suggested a positive argument for it. According to this argument, the transmission principle is entailed by the best explanation of joint satisfiability, because the best explanation of joint satisfiability involves the following transmission principle about reasons (which in turn entails the transmission principle):

Reason transmission: If $\mathrm{A}$ has a reason to $\phi$, and $\psi$-ing is an incompatible alternative to $\phi$-ing, then $\mathrm{A}$ has an equally strong reason to not $\psi$.

To illustrate, suppose that you have a reason to go to the Radiohead concert, and you also have a reason to go to the Portishead concert, but since both bands are playing on the same evening, you cannot see them both. Reason transmission entails that your reason to see Radiohead provides an equally strong reason against seeing Portishead, and vice versa. This rules 
out both of these options being favored by the balance of reasons, which explains joint satisfiability. At the same time, since not taking the necessary means to an action is always incompatible with performing that action, reason transmission licenses the transmission from reasons for actions to reasons for necessary means, thereby entailing the transmission principle. ${ }^{23}$

White puts forward two counterexamples to reason transmission. One of these examples is a contrary-to-duty scenario: a doctor can only attend to one of two patients; she has more reason to attend to the first patient (who needs her help more urgently) but will not in fact do this. Other things being equal, reason transmission entails that the doctor nevertheless has decisive reason to not attend to the second patient. White objects that the doctor would not, if she acted on that reason, be justified in her decision, and that this conflicts with the idea that "normally, if an agent has a decisive reason against $\phi$-ing, . . . and is aware of all the relevant facts of her situation, then, if she decides not to $\phi$ on the basis of that reason, this will constitute a justification for her decision." ${ }^{24}$ But contrary to what White assumes, if the doctor knows that she will not help the first patient, then it is not possible for her to refrain from helping the second patient on the basis of the instrumental reason that doing so is incompatible with helping the first patient. Acting for an instrumental reason requires an intention to conform to the relevant intrinsic reason, and it is conceptually impossible to have an intention for an action that one knows one will not perform. ${ }^{25}$

I therefore do not think that White's contrary-to-duty scenario provides a challenge for reason transmission that cannot be met in the way suggested in Section I. However, White also provides a counterexample that is not a contrary-to-duty scenario and that seems to provide independent reasons for rejecting reason transmission:

Suppose that A has several options available to her, w, x, y, and z. Assume that she has the same reason for each of the options but that she doesn't need to perform more than one of them-they are, say, each equally good, individually sufficient ways of achieving some end of hers. But now imagine that, while it would be possible for A to do any combination of $\mathrm{w}, \mathrm{x}$, and $\mathrm{y}$, it is not possible for her to do $\mathrm{z}$ to-

23. See Kiesewetter, "Instrumental Normativity," 944-46, for a more detailed version of this argument.

24. White, "Transmission Failures," 730.

25. This also explains why "it would plainly be disingenuous for the doctor to explain why she did not help patient 2 by citing the fact that there was another patient who was in greater need" (ibid.). The explanation is not that the greater need of patient 1 was not a reason to refrain from helping patient 2 , but simply that this fact was not her reason for doing so. 
gether with any of the other options. Given these assumptions, reason transmission entails that, other things equal, A has more reason not to do $\mathrm{z}$ as compared with her other options - and, therefore, that she should not do z. ${ }^{26}$

This, I agree, is an absurd conclusion-if reason transmission implies that A ought not to $z$ under such circumstances, there must be something wrong with it.

In what follows, I shall first argue that White's claim that reason transmission entails the absurd conclusion relies on a suppressed assumption about the aggregation of reasons, which should be rejected (Sec. III.A). Subsequently, I shall highlight a related problem that cannot be solved by rejecting assumptions about aggregation, but only by modifying reason transmission itself (Sec. III.B). Finally, I will outline a version of the envisaged argument from joint satisfiability to the transmission principle that works with the modified principle rather than the original one (Sec. III.C).

\section{A. The Independence Condition}

Let me start with the question whether in White's case reason transmission really entails that "A has more reason not to do $\mathrm{z}$ as compared with her other options," as White claims. This will be so if the reasons to do $z$ that derive from the reasons for $w, x$, and $y$ allow for aggregation, where reasons allow for aggregation when they are stronger in combination than each reason is on its own. ${ }^{27}$ It is a commonplace that not all considerations that we intuitively accept as reasons can be aggregated. Suppose, for example, that Anthony needs Bea's help with setting up his bookshelf, and that this is a reason for Bea to postpone her grocery shopping. If this is true, then, intuitively, it will also be true that the fact that Anthony needs Bea's help is a reason for Bea to postpone her grocery shopping. And it will also be true that the fact that someone needs Bea's help is a reason for her to postpone her grocery shopping. It is clear, however, that these reasons are not stronger in combination; they do not allow for aggregation. A natural way to capture this is to say that the relevant reasons are not "independent," 28 and accept the following restriction on reasons aggregation:

Independence condition: Reasons allow for aggregation only if they are independent.

26. Ibid., 729 .

27. Note that aggregation is weaker than additivity, according to which the combined weight of two reasons for an option equals the sum of the weights of the single reasons.

28. See, e.g., Mark Schroeder, Slaves of the Passions (Oxford: Oxford University Press, 2007), 125 . 
Independence, in turn, is naturally understood in terms of grounding: two reasons are independent if and only if (i) they aren't grounded in (or don't derive from) the same source reason and (ii) neither is grounded in (or derives from) the other. ${ }^{29}$

White's reductio of reason transmission violates the independence condition: it presupposes that instrumental reasons that derive from the same source reason, and which are thus dependent reasons, allow for aggregation. Since the independence condition is independently very plausible, as Bea's reasons illustrate, proponents of reason transmission need not be worried about White's objection.

\section{B. Optional Reasons}

The independence condition does not help, however, with another worry that one might have with applying reason transmission to a case like White's, which involves instrumental reasons for options that are "equally good, individually sufficient ways of achieving some end." I shall call such reasons "optional," by which I mean that one can fail to comply with them without any loss (or expected loss).$^{30}$ Note that optionality in this sense has to be distinguished from the property that a reason has if one can fail to comply with it without violating an obligation. Most reasons are optional in the second sense, but intrinsic (i.e., nonderivative) reasons are never optional in the sense I am concerned with, nor are derivative reasons for necessary or best means to comply with an intrinsic reason. Failure to comply with such reasons may be, all things considered, permitted or even required, but it nevertheless involves a loss. Failure to comply with a reason need not involve a loss, however, if the reason derives from a transmission principle that is more liberal than the following:

Best means transmission: If $\mathrm{A}$ has an intrinsic reason to $\phi,{ }^{31}$ and $\psi$ ing is a necessary part of every optimal sufficient means to $\phi$-ing, ${ }^{32}$ then $\mathrm{A}$ has a reason to $\psi$.

29. For this proposal, see Jan Gertken, "How the Numbers Count" (unpublished manuscript).

30. Some risk-related reasons are arguably such that one can fail to conform to them without any actual loss (see Kiesewetter, Normativity of Rationality, 176-78), but as long as one cannot fail to conform to them without expected loss, such reasons should be regarded as nonoptional in the sense relevant for the present discussion.

31. The restriction to intrinsic reasons is necessary in order to avoid what Bedke calls "the problem of subversion"; see Matthew S. Bedke, "The Iffiest Oughts: A Guise of Reasons Account of End-Given Conditionals," Ethics 119 (2009): 672-98, 679. For discussion, see Jan Gertken and Benjamin Kiesewetter, "Is There a Liberal Principle of Instrumental Transmission?" (unpublished manuscript), sec. 1 .

32. Although it is a natural question to ask what it is for a means to be good or optimal, this question is beyond the scope of this article-I have to rely on an intuitive under- 
The least controversial principle that allows us to derive such reasons seems to be the following:

Optimal means transmission: If A has an intrinsic reason to $\phi$, and $\psi$ ing is a necessary part of an optimal sufficient means to $\phi$-ing, then A has a reason to $\psi^{33}$

While White's reductio of reason transmission fails because it presupposes that dependent reasons allow for aggregation, one might also have a more general worry with the idea that optional reasons are subject to reason transmission - a worry that has nothing to do with aggregation. The worry is that the fact that $\phi$-ing is incompatible with $\psi$-ing does not really provide a reason against $\phi$-ing, as long as there is no intrinsic reason that can only be served (or is at least best served) by $\psi$-ing. To illustrate this point, suppose that the Talking Heads are giving a reunion concert, which you have reason to attend. There are two ticket counters, and buying the ticket at either of these counters is a necessary part of an optimal sufficient means to seeing the Talking Heads. Does the fact that buying the ticket at counter A is incompatible with buying the ticket at counter B speak against buying the ticket at counter A? Intuitively, this is the case only if buying the ticket at counter B serves some end that cannot equally well be served by buying the ticket at counter A. Thus, applying reason transmission to optional reasons yields counterintuitive results-results that have nothing to do with aggregation.

\section{The Argument for the Transmission Principle Revisited}

One might try to avoid this problem by rejecting optimal means transmission and all other transmission principles that let us derive optional reasons, but doing so has revisionary implications. If we grant the existence of optional reasons, in contrast, we need to restrict the transmission from reasons for options to reasons against incompatible options to nonoptional reasons:

standing here. I assume, however, that effectiveness is only one dimension of the goodness of a means. Another important dimension is the means' compatibility with conforming to intrinsic reasons other than the one that the means is supposed to facilitate.

33. Raz, Kolodny, and others propose much more liberal transmission principles, according to which we have reason to take about just any means to what we have intrinsic reason to do; see Joseph Raz, "The Myth of Instrumental Rationality," Journal of Ethics and Social Philosophy 1 (2005): 2-28; Niko Kolodny, "Instrumental Reasons," in The Oxford Handbook of Reasons and Normativity, ed. Daniel Star (Oxford: Oxford University Press, 2018), 731-63. However, these principles have controversial implications that optimal means transmission avoids (for discussion, see Gertken and Kiesewetter, "Is There a Liberal Principle of Instrumental Transmission?"). I here focus on what seems to me the weakest and most plausible transmission principle that lets us derive optional reasons. 
Nonoptional reason transmission: If A has a nonoptional reason to $\phi$, and $\psi$-ing is an incompatible alternative to $\phi$-ing, then $\mathrm{A}$ has an equally strong (nonoptional) reason not to $\psi$.

The crucial question is now whether this restricted principle can do the job that I intended the unrestricted principle to do. This will be so if (a) nonoptional reason transmission is part of the best explanation of joint satisfiability and (b) nonoptional reason transmission entails the transmission principle. I believe that there is reason for being optimistic with regard to both of these claims.

Remember that the class of nonoptional reasons includes both all intrinsic reasons and all instrumental reasons for actions that are necessary parts of every optimal means to complying with an intrinsic reason. Given this, the following seems to me a plausible assumption:

Supervenience hypothesis: What you ought to do depends only on your nonoptional reasons.

Recall your purely optional reason to buy the Talking Heads ticket at counter A. You do not have an intrinsic reason to do this, nor is doing so necessary for taking an optimal means to doing something you have intrinsic reason to do. It seems to follow that it's not the case that you ought to buy the ticket at counter A. Perhaps you ought to buy a ticket, or you ought to buy a ticket at [counter A or counter B]. But very plausibly, this will be so only if buying a ticket, or buying a ticket at [counter A or counter B], is a necessary part of every optimal sufficient means to seeing the Talking Heads (or doing something else you have intrinsic reason to do). For if we suppose that there are alternative, equally good means available, it seems again unwarranted to conclude that you ought to do these things. Thus, when asking what you ought to do, it looks like we can ignore your optional reasons and focus on your nonoptional reasons alone.

According to the supervenience hypothesis, obligations depend only on those reasons that are subject to nonoptional reason transmission. And if that is so, then the latter principle provides a good explanation for joint satisfiability. For all reasons that are relevant for whether you ought to $\phi$ will then provide equally strong reasons against incompatible options, thereby ruling out the possibility that, for each of two incompatible options, you have more reason to take it than not to take it. At the same time, nonoptional reason transmission seems to entail the transmission principle, since, according to it, all reasons that are relevant for whether you ought to $\phi$ provide equally strong reasons for taking the necessary means.

I conclude that the argument from joint satisfiability to the transmission principle can be defended by appeal to a modified version of reason transmission that is restricted to nonoptional reasons and therefore does 
not conflict with optimal means transmission and other, even more liberal transmission principles.

\section{CONCLUSION}

Actualists hold that contrary-to-duty scenarios are counterexamples to principles like joint satisfiability and the transmission principle. In this article, I have argued that a possibilist treatment of such scenarios, which can preserve both of these principles, is justifiable. I have also defended a direct argument for joint satisfiability, as well as an argument from joint satisfiability to the transmission principle. I hope to have shown that with respect to the notion of 'ought' that is used in conclusions of practical deliberation, the assumption of deontic dilemmas is untenable and actualism needs to be rejected. 